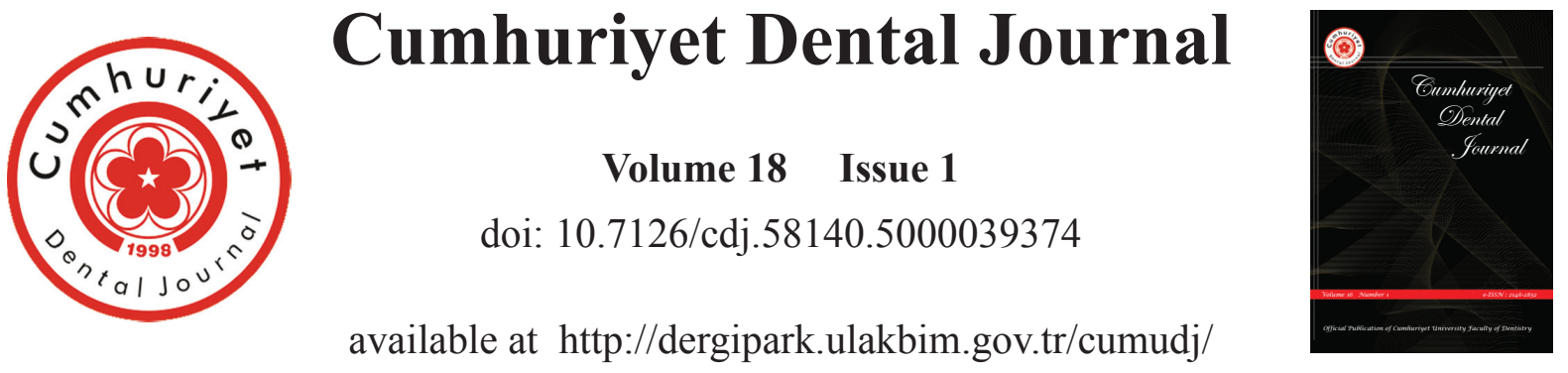

RESEARCH ARTICLE

\title{
Effectiveness of four rotary retreatment instruments during root canal retreatment
}

\author{
Hakan Gokturk, DDS, PhD, ${ }^{a}$ Ali Cagin Yucel, DDS, PhD, ${ }^{b}$ Aziz Sisman, BE, PhD \\ ${ }^{a}$ Department of Endodontics, Faculty of Dentistry, Gaziosmanpaşa University, Tokat, Turkey \\ ${ }^{b}$ Dentistanbul, Levent Academy, İstanbul, Turkey \\ 'Department of Geomatics Engineering, Engineering Faculty, Ondokuz Mayıs University, Samsun, Turkey
}

\section{A R T I C L E I N F O}

\section{Article history:}

Received 30 June 2014

Accepted 19 October 2014

\section{Keywords:}

Endodontics

Nickel

Titanium

Retreatment

\begin{abstract}
A B S T R A T
Objectives: The purpose of this in-vitro study was to investigate the residual root canal filling material after retreatment of root canals using stainless steel hand files, and four nickeltitanium retreatment instruments.

Materials and Methods: Seventy five extracted mandibular premolars were instrumented and filled. The samples were randomly divided into 5 groups $(n=15)$ and retreated using Hedström files, Mtwo R, R-Endo, ProTaper Universal Retreatment, and D-RaCe systems. The roots were digitally radiographed, then grooved split longitudinally to investigate the area of remaining filling material. The time of retreatment and the instruments fracture were also recorded. Results: The Hedström files left less filling material than the rotary retreatment instruments but a significant difference was found only in the middle third ( $p<0.01$ ). The apical third had the most residual gutta-percha and sealer compared to the coronal and middle thirds. The retreatment time for the $\mathrm{D}-\mathrm{RaCe}$ and ProTaper Universal Retreatment groups were significantly shorter than other groups $(\mathrm{p}<0.01$ ). Eight Mtwo R files, 2 ProTaper Universal Retreatment files and $1 \mathrm{R}$-Endo file were fractured.

Conclusions: All groups left residual root canal filling material inside the root canal walls. Nickel-titanium rotary retreatment instruments were faster than Hedström files but had a higher risk of instruments fracture.
\end{abstract}

\section{INTRODUCTION}

When root canal treatment do inadequate, treatment choices include non-surgical root canal retreatment, periradicular surgery, or extraction. Non-surgical root canal retreatment is often reported as the initial treatment option to resolve or decrease microbial infection, which is responsible for insufficient root canal treatment. The purpose of retreatment is entirely eject the

Corresponding author at: Dr. Hakan GOKTURK, Gaziosmanpaşa University Faculty of Dentistry, Department of Endodontics, Tokat, Turkey. Phone: +90-356-212 42 22, Fax:+90-356 21242 25, E-mail: gokturk82@hotmail.com 
filling material from the root canal to allow effective shaping, cleaning and filling of the root canal. ${ }^{1}$ Only if the gutta-percha and sealer can be removed entirely and the canal reached to the apical foramen, can be applied an appropriate retreatment procedures. ${ }^{1,2}$

Hand files, solvents, engine-driven rotary files, ultrasonic instruments, heat-carrying, and lasers are helpful instruments to remove especially guttapercha. ${ }^{1,3-8}$ Recently, nickel-titanium (NiTi) rotary instruments have been produced for retreatment procedure. A few examples of these systems is the R-Endo Retreatment (MicroMega, Besançon, France), the Mtwo R (VDW, Munich, Germany), the ProTaper Universal Retreatment (PTUR) (Dentsply Maillefer, Ballaigues, Switzerland), and the D-RaCe (FKG, Dentaire Sa, La Chauxde-Fonds- Switzerland). Only several studies $^{9,10}$ have investigated the efficacy of $\mathrm{D}-\mathrm{RaCe}$ instruments.

D-RaCe system has 2 files, DR1 (\#30.10) and DR2 (\#25.04). DR1 has an active tip and is used for two thirds of the root. DR2 has an in-active tip and is used for the apical third. The system files have a triangular cross section with alternating cutting edges. ${ }^{10}$

Mtwo $\mathrm{R}$ system has 2 instruments, R1 (\#15.05) and R2 (\#25.05) The Mtwo $\mathrm{R}$ instruments have an increasing pitch length, an S-shaped cross-section in the apical-coronal direction and a cutting tip. The system files are used for the entire working length (WL). ${ }^{11}$

PTUR system consists of 3 instruments: D1 (\#30.09), has an active tip, and is used for the coronal third. D2 (\#25.08), and D3 (\#20.07) have inactive tips and are used for the middle and apical thirds, respectively. The system files have a convex, triangular cross-section. ${ }^{12}$

R-Endo system consists of 4 instruments: Re (\#25.12) to prepare the first few millimeters (1-3mm) of the canal orifice, and R1, R2 and R3 devoted to each root canal third to a size \#25, with.08.,06 and.04 tapers, respectively. System has an optional finishing file Rs (\#30.04). The files have an inactive tip, no radial land, and a triangular cross-section with three equally spaced cutting edges. ${ }^{13}$

The aim of this study was to investigate the residual root canal filling material after the retreatment of root canals using stainless steel hand files (Hedström files), and four NiTi retreatment instruments (R-Endo, Mtwo R, PTUR, D-RaCe).

\section{MATERIAL AND METHODS}

The research proposal was submitted to review by the Ethics in Samsun Clinical Research Ethics Committee of the Ondokuz Mayıs University of Turkey (No. 2009-20), and the study design was approved.

\section{Specimen Preparation}

A total of 75 extracted human mandibular premolars with similar length having one single straight root canal, and no previous root canal treatment, calcification, resorption were used for the present study. Only teeth with fully formed apices were selected. To confirm the canal anatomy, preoperative digital radiographs of each root were taken by two directions (mesiodistal and buccolingual). Access cavity was opened with a high-speed hand tools with copious water spray. To obtain similar canal width, teeth were selected according to the following criteria; only roots in which a size \#10 K-file (VDW, Munchen, Germany) could slightly pass the apex but size a \#15 K-file firmly seated at the apical foramen were included in this study. The WL was established by extracting $0.5 \mathrm{~mm}$ from the tip of size \#10 K-file visualized on the apical foramen. The crowns were removed with 
steel discs and a novel measurement of $15 \mathrm{~mm}$ WL was obtained for each tooth, for more same specimens. Then the roots were immersed into self-cure $5 \mathrm{~mm}$ acrylic resin blocks (Orthoacril, Dentarium, Ispringen, Germany) except for coronal and apical $5 \mathrm{~mm}$ sections.

\section{Canal Preparation}

The root canal was enlarged by using the step-back technique. Preparation was completed with a size\#30 K-file reaching the full WL and step back in 1-mm increment to a file size \#50. Coronal flaring was established with Gates-Glidden burs sizes 3 and 2 . The canals were irrigated with $3 \mathrm{~mL}$ of $5.25 \% \mathrm{NaOCl}$ after each instrument's use. When the preparation of root canals was finished, for smear layer removal, $1 \mathrm{~mL}$ of $17 \%$ EDTA was used for $1 \mathrm{~min}$ and a final flush was performed using $10 \mathrm{~mL} 5.25 \%$ $\mathrm{NaOCl}{ }^{14}$ The root canals were then dried using paper points.

\section{Canal Filling}

The root canals were filled with $\mathrm{AH}$ Plus sealer (Dentsply DeTrey, Konstanz, Germany) and gutta-percha using lateral compaction technique. A standardized gutta-percha master cone (size 30; Dentsply, Switzerland) was coated with $\mathrm{AH}$ Plus sealer and placed into the root canal to the WL. A 25 spreader was used $2 \mathrm{~mm}$ short of WL. Accessory cones were then laterally condenced until they could not be introduced more than $1-2 \mathrm{~mm}$ into the canal. ${ }^{15}$ The filling was evaluated on digital radiographs in mesiodistal and buccolingual directions. When the root canal filling contained spaces, it was deemed inadequate and filled canals were recompacted. Coronal access was coated with temporary filling material (Cavit G; 3M Espe, Seefeld, Germany), and the teeth were stored at $37^{\circ} \mathrm{C}$ and $100 \%$ humidity for 30 days to allow the sealer to set entirely.

\section{Retreatment Technique}

The roots were randomly divided into five groups of 15 roots each. The temporary fillings were removed to open the root canals. No solvent was used during procedure. All instruments were used on a low-torque rotary engine driven motor (VDW Gold, VDW GmbH, Munich, Germany) in a crown-down technique, except for Mtwo R instruments. They were used with a single length technique.

\section{Group D-RaCe}

$\mathrm{D}-\mathrm{RaCe}$ retreatment file DR1 was used to remove sealer and gutta-percha from the coronal third of the root canal at $1000 \mathrm{rpm}$. DR2 was used at $600 \mathrm{rpm}$ to remove sealer and gutta-percha from the middle and apical third of the root canal.

\section{Group Mtwo R}

Mtwo R1 and R2 were used in a brushing action with a lateral pressing motion with full WL. The instruments were rotated at $300 \mathrm{rpm}$.

\section{Group PTUR}

PTUR files: the D1 file was used to remove sealer and gutta-percha from the coronal third of the root canal. The D2 file was used in the coronal two thirds of the root canal. The D3 file was used with mild apical pressure in the WL. The instruments were used at $500 \mathrm{rpm}$.

\section{Group R-Endo}

$\mathrm{R}$-Endo $\mathrm{Rm}$ file was used canal orifice to create a pathway, thus allowing the alignment and the centering of the next file. Re file was used to a deep of 1-3 mm towards to the apex with circumferential filing. An R1 instrument was used for the coronal third, R2 was used for the middle 
third, and R3 was used for the apical third. All instruments were used to remove filling material in a brushing circumferential movement. The instruments were used at $300 \mathrm{rpm}$.

\section{Group Hedström Files}

Gates-Glidden (Main Inc. Tochigi, Japan) size 3 and subsequently size 2 were used to remove coronal and middle filling material at $800 \mathrm{rpm}$. Hedström file (Thomas Hedström, Pneumat, Bourges, France) size \#25 and \#20 were used to remove apical filling using a circumferential quarter-turn push-pull filling motion.

The canals was irrigate with $3 \mathrm{~mL}$ of $5.25 \% \mathrm{NaOCl}$ at each instrument change. Ten $\mathrm{mL}$ of $5.25 \% \mathrm{NaOCl}$ was used for final irrigation.

All instruments were used to prepare three root canals only. Instruments were examined after every use; under a stereomicroscope at $10 \mathrm{X}$ magnification (Leica MZ 12.5, Heerbrugg, Germany) for signs of deformation. Any deformed instruments were discarded and also recorded.

A single operator prepared all specimens. Retreatment procedure was concluded to have been complete when the WL was achieved, the canal walls were clear and no more canal filling material could be removed with the instruments used. The retreatment time in seconds was calculated only in the active retreatment procedures, not including time for irrigation and change of instruments.

\section{Evaluation of Apical Extrusion}

Extrusion of debris through the apical foramen during retreatment was detected visually using dental loupe with $3 \mathrm{X}$ magnification and scored as follow: $0=$ no extrusion of filling material; 1=minimal extrusion of filling material, barely detectable; $2=$ moderate extrusion of filling material, easily detectable; and $3=$ extrusion of considerable amount of filling material. ${ }^{16}$

\section{Evaluation of Residual Filling Material}

The samples were digitally radiographed in mesiodistal and buccolingual directions. The images were transferred to a PC and NetCAD (NetCAD 5.0 GIS for Windows, Ak Engineering Computer LLC., Ankara, Turkey) was used to evaluate the area of remaining gutta-percha and sealer in the root canal. Each root canal was then divided into coronal, middle and thirds. The amount of residual filling material in each third was determined in square millimeters $\left(\mathrm{mm}^{2}\right)$ with NetCAD. The area of each third of the root canal, as measured in either the mesiodistal or buccolingual projections, was considered as $100 \%$. The total area of radio-opaque material in each third of each projection was measured. The values were used to calculate the total area of the canal and the residual filling material as a percentage (Figure 1 ).

The roots were grooved with a diamond disk, split longitudinally without damaging the inner layer of dentine around the canal

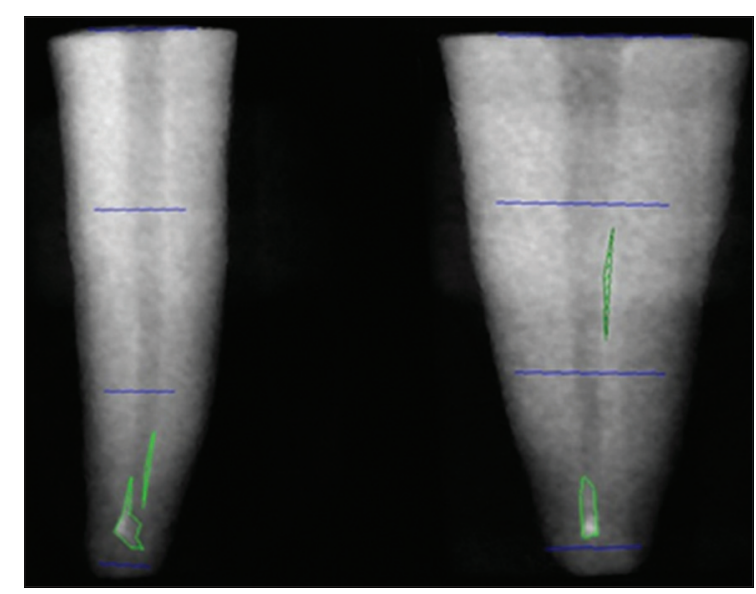

Figure 1. Gutta-percha and sealer remnants in the root. Buccolingual (a) and mesiodistal (b) views of root. 
and both root halfs photographed under a stereomicroscope with 10X magnification. Each third of the roots were evaluated separately for residual filling material. The areas of residual filling material on the canal walls were calculated in $\mathrm{mm}^{2}$ using NetCAD (Figure 2).

\section{Statistical Analysis}

Statistical analysis for residual filling material, and retreatment time was performed with ANOVA, Kruskal-Wallis and Mann-WhitneyU-tests with Bonferroni

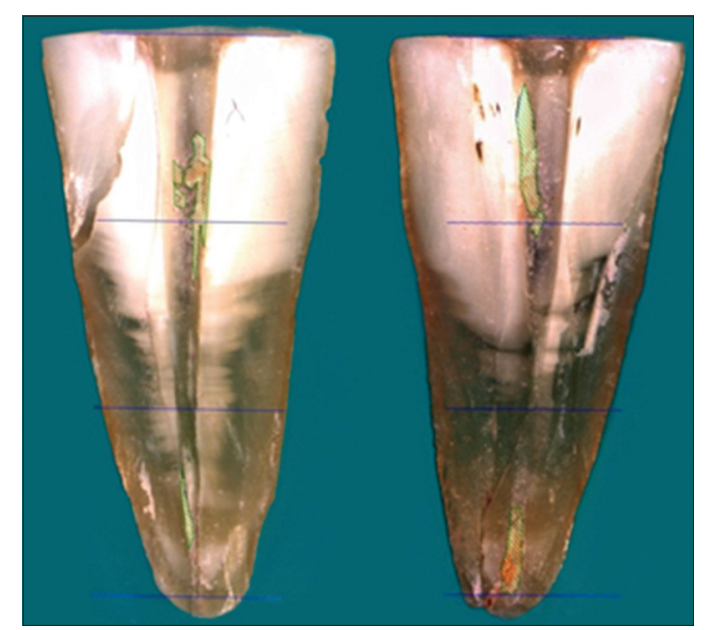

Figure 2. View of both root halves under stereomicroscope with 10X magnification. correction. The intraclass correlation coefficient (ICC, p) was calculated to estimate the congruity of radiographic and split longitudinally techniques.

\section{RESULTS}

The amount of remaining filling material for each group is presented in Table 1. All instruments left gutta-percha and sealer inside the root canal.

There was no significant difference among the groups in the apical and coronal canal third when evaluating residual filling material with the split longitudinally technique ( $p>0.05$ ). In the middle third, the Hedström files group left less filling material than the other groups but a significant difference was not found between the D-RaCe, PTUR and R-Endo groups ( $p>0.05)$.

The roots retreated with Hedström files leftless filling material inside the root canals than the other groups but a significant difference was not found in radiographic technique ( $p>0.05$ ). The apical third had the most residual gutta-percha and sealer compared to the coronal and middle thirds.

Table 1. The amount of residual gutta-percha and sealer (\%) for each group by means of split longitudinally and radiographic analysis.

\begin{tabular}{|l|c|c|c|c|c|c|}
\hline \multirow{2}{*}{ Groups } & \multicolumn{3}{|c|}{ Split Longitudinally } & \multicolumn{3}{c|}{ Radiographic } \\
\cline { 2 - 7 } & Coronal & Middle & Apical & Coronal & Middle & Apical \\
\hline D-RaCe & $7.05 \pm 6.66^{\dagger}$ & $20.97 \pm 10.13^{\S}$ & $48.40 \pm 13.17^{\dagger}$ & $2.91 \pm 4.81^{\dagger}$ & $18.42 \pm 13.31^{\dagger}$ & $49.71 \pm 26.41^{\dagger}$ \\
\hline Mtwo R & $10.71 \pm 10.84^{\dagger}$ & $10.23 \pm 5.57^{\ddagger}$ & $56.32 \pm 19.04^{\dagger}$ & $4.32 \pm 6.16^{\dagger}$ & $7.65 \pm 7.73^{\dagger}$ & $47.81 \pm 20.43^{\dagger}$ \\
\hline PTUR & $5.57 \pm 3.50^{\dagger}$ & $19.66 \pm 17.81^{\ddagger, \S}$ & $48 \pm 15.99^{\dagger}$ & $4.05 \pm 4.09^{\dagger}$ & $17.87 \pm 21.29^{\dagger}$ & $56.36 \pm 16.74^{\dagger}$ \\
\hline R-Endo & $14.78 \pm 13.94^{\dagger}$ & $19.39 \pm 18.73^{\ddagger, \S}$ & $41.59 \pm 14.41^{\dagger}$ & $8.78 \pm 13.27^{\dagger}$ & $15.65 \pm 24.27^{\dagger}$ & $42.01 \pm 23.92^{\dagger}$ \\
\hline Hedström & $4.01 \pm 1.82^{\dagger}$ & $6.01 \pm 1.64^{\dagger, \neq}$ & $41.18 \pm 17.97^{\dagger}$ & $2.01 \pm 3.61^{\dagger}$ & $4.79 \pm 5.94^{\dagger}$ & $39.97 \pm 23.46^{\dagger}$ \\
\hline & $*$ & $* *$ & $*$ & $*$ & $*$ & $*$ \\
\hline
\end{tabular}

Values are expressed as mean \pm SD. $(* p<0.05, * * p<0.01)$ 
When each method for evaluation of residual filling material on the root canal was statistically compared, the ICC value was 0.54 for the coronal thirds (95\% Confidence Interval $=0.369-0.689)$. The ICC value was 0.80 for middle thirds (95\% $\mathrm{CI}=0.709-0.873$ ), and 0.41 for apical thirds (95\% CI=0.208-0.585), as shown in Table 2. This means that for the two methods, the coronal, middle, and apical thirds had below average agreement, good agreement, below average agreement, respectively.

Three D-RaCe (DR2), 6 Mtwo R (4 Mtwo R1 and 2 Mtwo R2), 4 PTUR (D3), 9 R-Endo (4 R2, 5 R3) and 2 hand files (1 \#20 Hedström, 1 \#25 Hedström) showed visible signs of plastic deformation. Eight Mtwo R files (5 Mtwo R1, 3 Mtwo R2), 2 PTUR files (D3) and 1 R-Endo (R3) were fractured during retreatment procedures (Table 3 ).

The retreatment time with the D-RaCe and PTUR groups were significantly shorter than the other groups $(\mathrm{p}<0.01)$. Manual instrumentation with Hedström files was significantly slower than the other groups ( $p<0.01$ ). Mtwo R and R-Endo groups were significantly faster than the Hedström files group $(\mathrm{p}<0.01)$ (Table 3$)$.

\section{DISCUSSION}

Retreatment of previously filled root canals is the first of choice for the management of insufficient root canal treatment. ${ }^{17}$
However, removing as much filling material as possible from root canal systems seems essential in order to expose residual necrotic tissue or bacteria that may be responsible for periapical inflammation and failure.

Decoronation allows specimen standardization by eliminating some variables, such as root canal access and dental crown anatomy, thus providing a more credible comparison of the suggested retreatment techniques. ${ }^{18}$ Therefore in this study, the teeth were standardized to $15 \mathrm{~mm}$, so that different lengths could not create an impact on the results. ${ }^{14}$ Thus, the volume of gutta-percha and sealer was tried to be equal in all samples. The root canals were obturated using a cold lateral condensation technique since this technique has been used in many similar researches. ${ }^{16,19,20}$ Each instrument was used according to the manufacturers' recommendations.

Sealer and gutta-percha cannot be distinguished between each other using radiographs. ${ }^{21}$ Therefore, sealer and guttapercha were considered together.

In some previous retreatment studies $^{10,22-24}$, root canals were reshaped after retreatment.In this study, further enlargement was not performed because of to investigate only the efficacy of retreatment files.

The results of this present study showed that none of the group guaranteed complete removal of gutta-percha and

Table 2. Comparative analysis of the methods of evaluation.

\begin{tabular}{|l|c|c|c|}
\hline & Coronal (\%) & Middle (\%) & Apical (\%) \\
\hline Split Longitudinally & $8.42 \pm 9.25$ & $15.25 \pm 13.73$ & $47.09 \pm 16.77$ \\
\hline Radiographic & $4.41 \pm 7.48$ & $12.88 \pm 16.74$ & $47.17 \pm 22.60$ \\
\hline ICC & 0.54 & 0.80 & 0.41 \\
\hline p & 0.00 & 0.00 & 0.00 \\
\hline
\end{tabular}

Values are expressed as mean $\pm \mathrm{SD}$ 
Table 3. Time (s) required for retreatment and the number of procedural errors.

\begin{tabular}{|c|c|c|c|c|}
\hline Groups & File type & Deformed & Fractured & Time (s) \\
\hline \multirow[t]{2}{*}{$\mathrm{D}-\mathrm{RaCe}$} & DR1 (\#30.10) & 0 & 0 & $128.54 \pm 23.58^{\dagger}$ \\
\hline & DR2 (\#25.04) & 3 & 0 & \\
\hline \multirow[t]{2}{*}{ Mtwo R } & Mtwo R1 (\#15.05) & 4 & 5 & $183.01 \pm 34.46^{\ddagger}$ \\
\hline & Mtwo R2 (\#25.05) & 2 & 3 & \\
\hline \multirow[t]{3}{*}{ PTUR } & D1 (\#30.09) & 0 & 0 & $127.14 \pm 25.59^{\dagger}$ \\
\hline & D2 (\#25.08) & 0 & 0 & \\
\hline & D3 (\#20.07) & 4 & 2 & \\
\hline \multirow[t]{5}{*}{ R-Endo } & Rm (\#25.04) & 0 & 0 & $181.22 \pm 31.67^{\ddagger}$ \\
\hline & $\operatorname{Re}(\# 25.12)$ & 0 & 0 & \\
\hline & R1 (\#25.08) & 0 & 0 & \\
\hline & R2 (\#25.06) & 4 & 0 & \\
\hline & R3 (\#25.04) & 5 & 1 & \\
\hline \multirow[t]{5}{*}{ Hedström files } & Gates Glidden 3 & 0 & 0 & $316.40 \pm 53.85^{\S}$ \\
\hline & Gates Glidden 2 & 0 & 0 & \\
\hline & \# 20 Hedström & 1 & 0 & \\
\hline & \# 25 Hedström & 1 & 0 & \\
\hline & & & & $* *$ \\
\hline
\end{tabular}

Values are expressed as mean \pm SD. $(* * p<0.01)$.

sealer, as previously reported. ${ }^{10,11,14,18,23,25}$ In addition, it has been reported that some filling material is always left in the root canal regardless of the technique used. ${ }^{3,26}$ The radiographic evaluation found no significant difference between the groups in the removal of gutta-percha and sealer in the different root thirds ( $p>0.05$ ). On the other hand, in the split longitudinally analysis, the Hedström files group removed significantly more filling material than R-Endo, PTUR and D-RaCe groups in the middle root thirds.
When comparing the two techniques for the detection of filling remains, the split longitudinally technique gave a more correct diagnosis than radiographic technique (Table 2). This result was reported in previous research. ${ }^{25,27}$ The radiographic technique provides only two-dimensional information on a three-dimensional structure and may be related to distortion and magnification. Furthermore, small amount of filling material may not be determined in radiography. ${ }^{28}$ In the split longitudinally technique, remaining filling 
material could be lost during separation of roots. ${ }^{29,30}$ Both techniques have specific limitations, and ideally, a nondestructive three-dimensional visualization of the root canal system would ensure a better determination of the filling material after retreatment. Nevertheless, micro-CT software does not provide a tool to section the specimen into equal thirds, so it was not possible to evaluate the remaining of sealer and gutta-percha according to root canal thirds. ${ }^{10}$

The largest amounts of remaining filling material were observed in the apical third, compared to the middle and coronal thirds. Previous studies supported these findings..$^{13,16,24}$ The presence of residual filling material in the apical third may well explain the presence of these lessinstrumented parts. ${ }^{31}$ By contrast, Zmener et $\mathrm{al}^{32}$ observed more filling material in the middle third than in the apical and coronal thirds in the oval-shaped root canal. Similarly Rödig et $\mathrm{al}^{10}$ reported that, $\mathrm{D}-\mathrm{RaCe}$ instruments showed significantly less residual sealer and gutta-percha compared with PTUR instruments and hand files in curved root canals.

The Hedström files group left less filling material in all root thirds. Previous studies supported these findings. ${ }^{16,28,33}$ The absence of sealer and gutta-percha in the middle and coronal parts was not surprising, since the use of a non-end cutting bur such as a Gates Glidden drills is a well known instruments for gutta-percha removal from the middle and coronal parts of the root canal. ${ }^{5}$ Gates Glidden drills were used safely in this study owing to the use of straight root canals. A previous ex vivo study ${ }^{34}$ Gates Glidden drills removed more gutta-percha and sealer than PTUR system in middle and coronal thirds. In the apical thirds it should also be considered that hand files which used the tactile sensation indicates the presence of filling material may have provide an advantage than rotary retreatment files. Similarly Takahashi et $\mathrm{a}^{12}$ reported that, hand files and Gates Glidden drills leave less remnants inside the root canal than PTUR files.

It is observed that, root filling material can be removed faster with rotary instruments than manual instrumentation. ${ }^{10,13,23}$ In this study, all NiTi rotary retreatment file groups were significantly faster than the Hedström files group in removing filling material. This probably occurred since the rotary movement might have produced frictional heat to further soften the gutta-percha, making it easier to remove and thus requiring less time. ${ }^{25,35} \mathrm{D}-\mathrm{RaCe}$ and PTUR groups required less time for the retreatment procedure with no significant difference them. DR1 (\#30.10) in D-RaCe and D1 (\#30.09) in the PTUR file with a special coronal enlargement files required less time than other NiTi rotary retreatment files. The total number of files used during retreatment was for $\mathrm{D}-\mathrm{RaCe}$, two; and for PTUR, three. These factors may be an advantage for both of the systems. Nevertheless, Barrieshi-Nusair ${ }^{36}$ and Unal et $\mathrm{al}^{28}$ found that both stainless steel hand files and NiTi were effective in removing filling material from the root canal system, though hand files were faster.

Another aim of the present study was to investigate the amount of apically extruded filling material during processing. Apical extrusion of debris might lead to postoperative discomfort, inflammation, and pain. ${ }^{37}$ Apical extrusions could be observed in all groups expect for Mtwo $\mathrm{R}$ in this study (Table 4). On the other hand, Mtwo $\mathrm{R}$ instruments left more debris in the apical third. The $\mathrm{D}-\mathrm{RaCe}$ group revealed greater extruded debris. The DR2 file was used at a constant speed of $600 \mathrm{rpm}$ in the apical third. This may be the reason why more gutta-percha and sealer were apically extruded. As a result, it is impossible to do retreatment of a root 
Table 4. Apical extrusion

\begin{tabular}{|l|c|c|c|c|}
\hline Groups & $\begin{array}{c}\text { Score } \\
0\end{array}$ & $\begin{array}{c}\text { Score } \\
1\end{array}$ & $\begin{array}{c}\text { Score } \\
2\end{array}$ & $\begin{array}{c}\text { Score } \\
3\end{array}$ \\
\hline D-RaCe & 12 & 2 & 1 & - \\
\hline Mtwo R & 15 & - & - & - \\
\hline PTUR & 14 & - & 1 & - \\
\hline R-Endo & 13 & 1 & 1 & - \\
\hline $\begin{array}{l}\text { Hedström } \\
\text { files }\end{array}$ & 13 & 2 & - & - \\
\hline
\end{tabular}

canal system chemomechanically without any extrusion of debris. The results of apical extrusion are similar with other apical extrusion studies. ${ }^{28,38}$ The Hedström files, R-Endo, and PTUR groups extruded similar amounts of debris.

According to earlier studies, NiTİ rotary files have a higher risk of instrument fractures than hand files. ${ }^{39,40}$ Although each instrument was used according to the manufacturer's instructions, 8 Mtwo R, 2 PTUR, and 1 R-Endo instrument fractured. No Hedström or D-RaCe file fractured. $\mathrm{D}-\mathrm{RaCe}$ instruments have alternating cutting edges which prevent threading, so that fracture incidence was decreased. Also, $\mathrm{D}-\mathrm{RaCe}$ instruments were used at 600 and $1000 \mathrm{rpm}$ according to the manufacturer's instruction. This was confirmed in other studies ${ }^{36,41}$ in which higher rpms showed no breakage and less deformed instruments during root canal preparation. The taper of the PTUR D3 (\#20.07) file is greater taper than for other instruments that were used to clean the apical part of the canals. Earlier studies reported that, taper was revealed to be a significant factor in determining fracture possibility for rotary NiTi instruments. ${ }^{30,42}$ The findings of this present study coherent with these previous results. Similarly Unal et $\mathrm{al}^{28}$ reported that in curved root canals, 5 (3 D3, 2 D2) files fractured in the PTUR and $2 \mathrm{R} 3$ in the $\mathrm{R}$-Endo groups. Initial orifice enlargement has been suggested to open the orifice of the canal for the smaller-taper files to pass more smoothly to the apex with less stress. ${ }^{43}$ The Mtwo R group, which had no initial orifice enlargement, was the more deformed group. Although Mtwo R files have a cutting tip, the small core of Mtwo $\mathrm{R}$ files could not provide adequate resistance to perforate the gutta-percha mass. The Hedström files group was the less deformed group and had no instruments fractured. The use of Gates Glidden drills and the tactile sensation may have provided an advantage for the Hedström files group.

\section{CONCLUSIONS}

The residual root canal filling was determined inside the root canal walls in all groups. Hedström files produced cleaner canals than rotary $\mathrm{NiTi}$ retreatment instruments, while rotary NiTi retreatment instruments were significantly faster than Hedström files in the removal of filling material.

\section{ACKNOWLEDGMENTS}

This study was supported by the Projects Management Office of the University of Ondokuz Mayıs University, Turkey (PYO. DİS.1904.10.007).

\section{REFERENCES}

1. Friedman $S$, Stabholz A, Tamse A. Endodontic retreatment--case selectionand technique.3. Retreatment techniques. J Endod 1990;16:543-549.

2. Friedman $S$, Stabholz A. Endodontic retreatment case selection and technique. Part 2: Treatment planning for retreatment. J Endod 1988;14:607-614. 
3. Wilcox LR, Krell KV, Madison S, Rittman B. Endodontic retreatment: evaluation of gutta-percha and sealer removal and canal reinstrumentation. J Endod 1987;13:453-457.

4. Wilcox LR. Endodontic retreatment: ultrasonics and chloroform as the final step in reinstrumentation. J Endod 1989;15:125-128.

5. Zakariasen KL, Brayton SM, Collinson DM. Efficient and effective root canal retreatment without chloroform. J Can Dent Assoc 1990;56:509-512.

6. Teplitsky PE, Rayner D, Chin I, Markowsky R. Guttapercha removal utilizing GPX instrumentation. J Can Dent Assoc 1992;58:53-58.

7. Hülsmann $M$, Stotz S. Efficacy, cleaning ability and safety of different devices for gutta-percha removal in root canal retreatment. Int Endod J 1997;30:227-233.

8. Viducic D, Jukic S, Karlovic Z, Bozic Z, Miletic I, Anic I. Removal of gutta-perchafromrootcanalsusing an $\mathrm{Nd}$ : YAGlaser. Int Endod $\mathrm{J}$ 2003;36:670-673.

9. Marques da Silva B, Baratto-Filho F, Leonardi DP, Henrique Borges A, Volpato L, Branco Barletta F. Effectiveness of ProTaper, D-RaCe, and Mtwo retreatment files with and without supplementary instruments in the removal of root canal filling material. Int Endod J 2012;45:927-932.

10. Rödig T, Hausdörfer T, Konietschke F, Dullin C, Hahn W, Hülsmann M. Efficacy of D-RaCe and ProTaper Universal Retreatment NiTi instruments and hand files in removing gutta-percha from curved root canals - a micro-computed tomography study. Int Endod J 2012;45:580-589.

11. Bramante CM, Fidelis NS, Assumpção TS, Bernardineli N,
Garcia RB, Bramante AS, de Moraes IG. Heat release, time required, and cleaning ability of MTwo R and ProTaper universal retreatment systems in the removal of filling material. J Endod 2010;36:1870-1873.

12. Takahashi CM, Cunha RS, de Martin AS, Fontana CE, Silveira CF, da Silveira Bueno CE. In vitro evaluation of the effectiveness of ProTaper universal rotary retreatment system for gutta-percha removal with or without a solvent. J Endod 2009;35:1580-1583.

13. Fenoul G, Meless GD, Pérez F. The efficacy of R-Endo rotary $\mathrm{NiTi}$ and stainless-steel hand instruments to remove gutta-percha and Resilon. Int Endod J 2010;43:135-141.

14. Marfisi $K$, Mercade $M$, Plotino $G$, Duran-Sindreu F, Bueno R, Roig M. Efficacy of three different rotary files to remove gutta-percha and Resilon from root canals. Int Endod J 2010;43:1022-1028.

15. Chu $\mathrm{CH}$, Lo EC, Cheung GS. Outcome of root canal treatment using Thermafil and cold lateral condensation filling techniques. Int Endod J 2005;38:179-185.

16. Somma F, Cammarota G, Plotino G, Grande NM, Pameijer $\mathrm{CH}$. The effectiveness of manual and mechanical instrumentation for the retreatment of three different root canal filling materials. J Endod 2008;34:466-469.

17. Hülsmann $M$, Drebenstedt $S$, Holscher C. Shaping and filling root canals during root canal re-treatment. Endodontic Topics 2011;19:74-124.

18. Dall'Agnol C, Hartmann MS, Barletta FB. Computed tomography assessment of the efficiency of different techniques for removal of root canal filling material. Braz Dent J 2008;19:306-312.

19. Gu LS, Ling JQ, Wei $X$, Huang $X Y$. 
Efficacy of ProTaper Universal rotary retreatment system for gutta-percha removal from root canals. Int Endod J 2008;41:288-295.

20. Tasdemir T, Er K, Yildirim T, Celik D. Efficacy of three rotary $\mathrm{NiTi}$ instruments in removing guttapercha from root canals. Int Endod J 2008;41:191-196.

21. Schirrmeister JF, Hermanns P, Meyer KM, Goetz F, Hellwig E. Detectability of residual Epiphany and guttapercha after root canal retreatment using a dental operating microscope and radiographs--an ex vivo study. Int Endod J 2006;39:558-565.

22. Saad AY, Al-Hadlaq SM, Al-Katheeri $\mathrm{NH}$. Efficacy of two rotary $\mathrm{NiTi}$ instruments in the removal of GuttaPercha during root canal retreatment. J Endod 2007;33:38-41.

23. Giuliani V, Cocchetti R, Pagavino G. Efficacy of ProTaper universal retreatment files in removing filling materials during root canal retreatment. J Endod 2008;34:1381-1384.

24. Aydin B, Köse $T$, Calişkan MK. Effectiveness of HERO 642 versus Hedström files for removing guttapercha fillings in curved root canals: an ex vivo study. Int Endod $\mathrm{J}$ 2009;42:1050-1056.

25. Kfir A, Tsesis I, Yakirevich E, Matalon S, Abramovitz I. The efficacy of five techniques for removing root filling material: microscopic versus radiographic evaluation. Int Endod J 2012;45:35-41.

26. Zuolo ML, Imura $\mathrm{N}$, Ferreira MO. Endodontic retreatment of thermafil or lateral condensation obturations in post space prepared teeth. J Endod 1994;20:9-12.

27. de Carvalho Maciel AC, Zaccaro Scelza MF. Efficacy of automated versus hand instrumentation during root canal retreatment: an ex vivo study. Int Endod J 2006;39:779-784.
28. Unal GC, Kaya BU, Taç AG, Keçeci AD. A comparison of the efficacy of conventional and new retreatment instruments to remove gutta-percha in curved root canals: an ex vivo study. Int Endod J 2009;42:344-350.

29. Masiero AV, Barletta FB. Effectiveness of different techniques for removing gutta-percha during retreatment. Int Endod J 2005;38:2-7.

30. Schirrmeister JF, Wrbas KT, Schneider $\mathrm{FH}$, Altenburger MJ, Hellwig E. Effectiveness of a hand file and three nickel-titanium rotary instruments for removing gutta-percha in curved root canals during retreatment. Oral Surg Oral Med Oral Pathol Oral Radiol Endod 2006;101:542-547.

31. Schirrmeister JF, Wrbas KT, Meyer KM, Altenburger MJ, Hellwig E. Efficacy of different rotary instruments for gutta-percha removal in root canal retreatment. J Endod 2006;32:469-472.

32. Zmener $\mathrm{O}$, Pameijer $\mathrm{CH}$, Banegas $\mathrm{G}$. Retreatment efficacy of hand versus automated instrumentation in ovalshaped root canals: an ex vivo study. Int Endod J 2006;39:521-526.

33. Hammad M, Qualtrough A, Silikas N. Three-dimensional evaluation of effectiveness of hand and rotary instrumentation for retreatment of canals filled with different materials. J Endod 2008;34:1370-1373.

34. Só MV, Saran C, Magro ML, VierPelisser FV, Munhoz M. Efficacy of ProTaper retreatment system in root canals filled with gutta-percha and two endodontic sealers. J Endod 2008;34:1223-1225.

35. Hülsmann $M$, Bluhm V. Efficacy, cleaning ability and safety of different rotary $\mathrm{NiTi}$ instruments in root canal retreatment. Int Endod J 2004;37:468-476.

36. Barrieshi-Nusair KM. Gutta-percha retreatment: effectiveness of nickel- 
titanium rotary instruments versus stainless steel hand files. $\mathrm{J}$ Endod 2002;28:454-456.

37. Seltzer S, Naidorf IJ. Flare-ups in endodontics. I. Etiological factors. J Endod 1985;11:472- 478.

38. Huang $X$, Ling $J$, Wei $X, G u$ L. Quantitative evaluation of debris extruded apically by using ProTaper Universal Tulsa rotary system in endodontic retreatment. $\mathrm{J}$ Endod 2007;33:1102-1125.

39. Imura N, Kato AS, Hata GI, Uemura M, Toda T, Weine F. A comparison of the relative efficacies of four hand and rotary instrumentation techniques during endodontic retreatment. Int Endod J 2000;33:361-366.

40. Betti LV, Bramante CM. Quantec SC rotary instruments versus hand files for gutta-percha removal in root canal retreatment. Int Endod J 2001;34:514-519.

41. Daugherty DW, Gound TG, Comer TL. Comparison of fracture rate, deformation and efficiency between rotary endodontic instruments driven at $150 \mathrm{rpm}$ and $350 \mathrm{rpm}$. J Endod 2001;27:93-95.

42. Haikel $Y$, Serfaty $R$, Bateman $G$, Senger B, Allemann C. Dynamic and cyclic fatigue of engine-driven rotary nickeltitanium endodontic instruments. J Endod 1999;25:434-440.

43. Bryant ST, Dummer PM, Pitoni C, Bourba M, Moghal S. Shaping ability of.04 and.06 taper ProFile rotary nickel-titanium instruments in simulated root canals. Int Endod $\mathrm{J}$ 1999;32:155-164.

How to cite this article: Hakan Gokturk, Ali Cagin Yucel, Aziz Sisman. Effectiveness of Four Rotary Retreatment Instruments During Root Canal Retreatment. Cumhuriyet Dent J 2015;18(1):25-36. 